\title{
High-Resolution Satellite Observations of A New Hazard of Golden Tides Caused by Floating Sargassum in Winter in the Yellow Sea
}

\author{
Qianguo Xing, Ruihong Guo, Lingling Wu, Deyu An, Ming Cong, Song Qin, Xuerong Li
}

\begin{abstract}
A new marine hazard of golden tides caused by floating brown macroalgae-Sargassum occurred in the Yellow Sea in December 2016. An economic loss of 0.5 billion CNY (about 73 million USD) was estimated due to damaged seaweed aquaculture in the Jiangsu Shoal, China. In this study, images from the new Chinese satellite of Gaofen (GF) with high-resolution optical cameras are used to retrieve the drifting path of floating Sargassum and its origin. A southward drifting path of floating Sargassum in the western Yellow Sea is identified for the first time, and the initial site of bloom occurrence is near the eastern end of the Shandong Peninsula, China, implying the origin of this hazard of floating Sargassum. The scale of this Sargassum bloom event in the Jiangsu Shoal is also evaluated using a linear mixing model suitable for high-resolution images. The result shows that the total area of Sargassum-containing pixels in the GF-1WFV images on 31-Dec-2016 was more than 46 $\mathbf{k m}^{2}$; and according to the estimation by the linear mixing model, the total area of sea surface completely covered by Sargassum was above $8.8 \mathrm{~km}^{2}$. The approach and the results presented in this work should contribute to future study and management of golden tides in Chinese coastal waters.
\end{abstract}

Index Terms - Gaofen satellite, high-resolution remote sensing, linear spectral mixing, floating macroalgae, Sargassum horneri, the Yellow Sea, the East China Sea

\section{INTRODUCTION}

$\mathrm{G}$ olden tides caused by brown macroalgae (Sargassum) and green tides caused by green macroalgae (Ulva spp.) were reported to have increased in recent years [1], [2]-[4]. At the end of December 2016, the seaweed farming area of Poryphyra yezoensis in the Jiangsu Shoal of the Yellow Sea was severely affected by floating brown macroalgae, which was identified as Sargassum horneri. At the sites severely affected by drifting Sargassum, the Poryphyra yezoensis aquaculture facilities were taken over by

Manuscript received on March 27, 2017; revised mm dd, 2017; accepted $\mathrm{mm} \mathrm{dd}, 2017$. Date of publication $\mathrm{mm} \mathrm{dd,} \mathrm{2017;} \mathrm{date} \mathrm{of} \mathrm{current} \mathrm{version} \mathrm{mm} \mathrm{dd,}$ 2017. This work was supported by the National Natural Science Foundation of China (No.41676171), the Qingdao National Laboratory for Marine Science and Technology of China (No.2016ASKJ02) and the Chinese Academy of Sciences (No.XDA1 1020403).

Q. Xing, R. Guo, L. Wu, D. An, M. Cong and X. Li are with the Yantai Institute of Coastal Zone Research, Chinese Academy of Sciences, and the University of Chinese Academy of Sciences. No.17, Chunhui road, Yantai, Shandong, 264003 China. (e-mails: qgxing@yic.ac.cn, rhguo@yic.ac.cn, linglingwu@yic.ac.cn, dyan@yic.ac.cn, mcong@yic.ac.cn and xrli@yic.ac.cn, respectively)
Sargassum and collapsed. Field survey conducted by an investigation team in Jiangsu Province showed that the size of the Sargassum rafts reached approximately 0.33 ha [5]. By a rough estimate, the area of Poryphyra yezoensis aquaculture zone that was affected by the floating Sargassum horneri in Jiangsu Province was about 22,700 ha, and most of the aquaculture zone faced loss in yield. The direct economic loss caused by this sudden take-over of golden tides was more than 0.5 billion CNY (about 73 million USD), which is the largest direct economic loss in seaweed aquaculture caused by floating Sargassum in China, and is comparable to the cleanup cost of green macraolgae (Ulva prolifera) just before the 2008 Olympic sailing venue in Qingdao, China [6], [7].

Direct economic loss by golden tides in China's coastal zones has never been documented before. To predict this new hazard of floating Sargassum and to mitigate its potential impacts, it is essential to know how gold tides form. Satellite images in archive may be the best data source for retrieving the drifting path of floating Sargassum and exploring their origin. In the past 10 years, satellite remote sensing was successfully used to investigate large-scale macroalgal blooms (MABs) around the world [2], [4], [6], [8]-[11]; however, these studies mainly relied on the moderate- and low-resolution satellite images, e.g., the $250 \mathrm{~m}$ bands of MODerate-resolution Imaging Spectroradiometer (MODIS) [6], [11], the $30 \mathrm{~m}$ bands of Huanjing-1 (HJ-1) [12]. For small-scale MABs, especially at their initial phases, it is necessary to use satellite images with high spatial resolution to detect the macroalgae rafts. In this research, high spatial resolution optical images are used to extract the spatio-temporal information of floating Sargassum to reveal their distribution, the drifting path, and to demonstrate the capabilities of high-resolution optical satellite images in monitoring this new marine hazard of golden tides.

\section{METHODS AND DATA}

\section{A. High-resolution satellite data}

In recent years, a series of new satellites with high spatial resolution (Gaofen, GF) were launched by China, which enables more efficient observations of subtle signals for the early stage of hazard. In this work, GF optical images with the cloud cover lower than $80 \%$ are collected over the Yellow Sea and its adjacent waters. With the merits of high resolution (16 $\mathrm{m})$, wide swath $(800 \mathrm{~km}$ ) and high revisit frequency (4 days), images captured by the Wide-Field-of-View (WFV) cameras of GF-1 are used to detect floating Sargassum over the whole 
Yellow Sea from September 2016, i.e., after the MAB caused by the green macroalgae of Ulva prolifera in the summer of 2016; meanwhile, high-resolution images acquired by the
Panchromatic and MultiSpectral sensors (PMS) of GF-1 and GF-2 are used for validation over optically-complex waters. Please see Table 1 for the optical sensors used in this work. Table 1 Sensor characteristics of sun-synchron, polar-orbit satellites of Gaofen (GF-1, GF-2)*

\begin{tabular}{|c|c|c|c|}
\hline Satellite & \multicolumn{2}{|c|}{ GF-1 } & GF-2 \\
\hline Sensors & $\begin{array}{c}\text { WFV } \\
\text { (wide-field-view) }\end{array}$ & $\begin{array}{c}\text { PMS (Pan-MSS, } \\
\text { panchromatic and } \\
\text { multispectral) }\end{array}$ & $\begin{array}{c}\text { PMS (Pan-MSS, } \\
\text { Panchromatic and } \\
\text { multispectral) }\end{array}$ \\
\hline MSS Band $1, \mu \mathrm{m}$ & $0.45-0.52$ & $0.45-0.52$ & $0.45-0.52$ \\
\hline MSS Band 2, $\mu \mathrm{m}$ & $0.52-0.59$ & $0.52-0.59$ & $0.52-0.59$ \\
\hline MSS Band $3, \mu \mathrm{m}$ & $0.63-0.69$ & $0.63-0.69$ & $0.63-0.69$ \\
\hline $\begin{array}{l}\text { MSS Band 4, } \mu \mathrm{m} \\
\text { (resolution) }\end{array}$ & $\begin{array}{c}0.77-0.89 \\
(16 \mathrm{~m})\end{array}$ & $\begin{array}{l}0.77-0.89 \\
\quad(8 \mathrm{~m})\end{array}$ & $\begin{array}{l}0.77-0.89 \\
\quad(4 \mathrm{~m})\end{array}$ \\
\hline $\begin{array}{c}\text { Pan band, } \mu \mathrm{m} \\
\text { (resolution) }\end{array}$ & - & $\begin{array}{c}0.45-0.90 \\
(2 \mathrm{~m})\end{array}$ & $\begin{array}{c}0.45-0.90 \\
(1 \mathrm{~m})\end{array}$ \\
\hline Swath & $800 \mathrm{Km}$ (4 cameras) & $60 \mathrm{Km}$ (2 cameras) & $45 \mathrm{Km}$ (2 cameras) \\
\hline Revisit cycle & \multicolumn{2}{|c|}{4 days } & 5 days \\
\hline Data period & \multicolumn{2}{|c|}{ April 26, 2013 - present } & August 19, 2014-present \\
\hline
\end{tabular}

\section{B. Data processing}

The image digital number (DN) values are first converted to radiance $\left(\mathrm{L}, \mathrm{W} \mathrm{m}{ }^{-2} \mathrm{sr}^{-1} \mu \mathrm{m}^{-1}\right.$ ) according to the calibration coefficients of gains and offsets: $\mathrm{L}=$ Gain*DN+Offset. Then, for the GF-1 WVF images, the ENVI ${ }^{\mathrm{TM}}$ FLAASH (Fast Line of sight Atmospheric Analysis of Spectral Hypercubes) atmospheric correction module is used to transfer the radiance to the ground reflectance (unitless). The index of Difference Vegetation Index (DVI), which shows good performance in reducing the impacts from sun glint and thin clouds compared to the Normalized Difference Vegetation Index (NDVI) [12], is derived from the GF-1 reflectance spectra, and used to detect MABs together with the RGB color composite image by visual inspection. See Eq. (1) for the calculation of DVI:

$\mathrm{DVI}=\mathrm{R}_{N I R}-\mathrm{R}_{R E D}$, (1)

where $\mathrm{R}_{N I R}$ and $\mathrm{R}_{R E D}$ are the surface reflectance of the near-infrared band and the red band at the ground level, respectively.

To extract as many macroalgae pixels as possible, each image is segmented into small windows. Then, the $\mathrm{R}$ (band 4)-G(band 3)-B(band 2) false-color image and the DVI images are used for visual inspection of each window where macroalgae show red or brown color in 432 image and higher DVI values than the background seawater. Finally, a threshold of DVI is set to extract the macroalgae pixels window by window, e.g., DVI $>-0.010$ or -0.015 , which changes slightly with water surface optical conditions. This approach can reduce the chance of mis-classification of macroalgae under optically complex water conditions [12], [13]. The PMS images with higher resolutions $(1,2,4$ and $8 \mathrm{~m})$ are also used to check the details for further validation. The area affected by floating macroalgae is manually outlined, and a time series of spatial distribution is generated.

\section{Estimation of Sargassum abundance}

The sizes of floating Sargarssum horneri in this study are usually smaller than the spatial resolution of images (e.g., 16 $\mathrm{m}$ of GF-1 WVF), which means that there is a sub-pixel mixing issue in estimating macroalgae abundance in each pixel. In this study, for large-scale floating macroalgae under clear sky condition, the total abundance of macroalgae is estimated with a simplified linear-mixing reflectance model of floating Sargassum and sea water. At first, the endmember reflectance ( $R$, unitless) of Sargarssum horneri and that of sea water were measured on 27-Feb-2017 in the Jiangsu Shoal. Then, a linear mixing approach is used for generating a group of reflectance with different portions of sea water and Sargassum (1-100\%) (Fig. 1), and the corresponding DVI values are calculated and normalized, with the minimum and maximum of 0 and 1 ([01DVI]), respectively. A regression model is then established by fitting a linear equation between the $[01 \mathrm{DVI}]$ and the portion of covering surface (PCS, \%). Eq. (2) is the model:

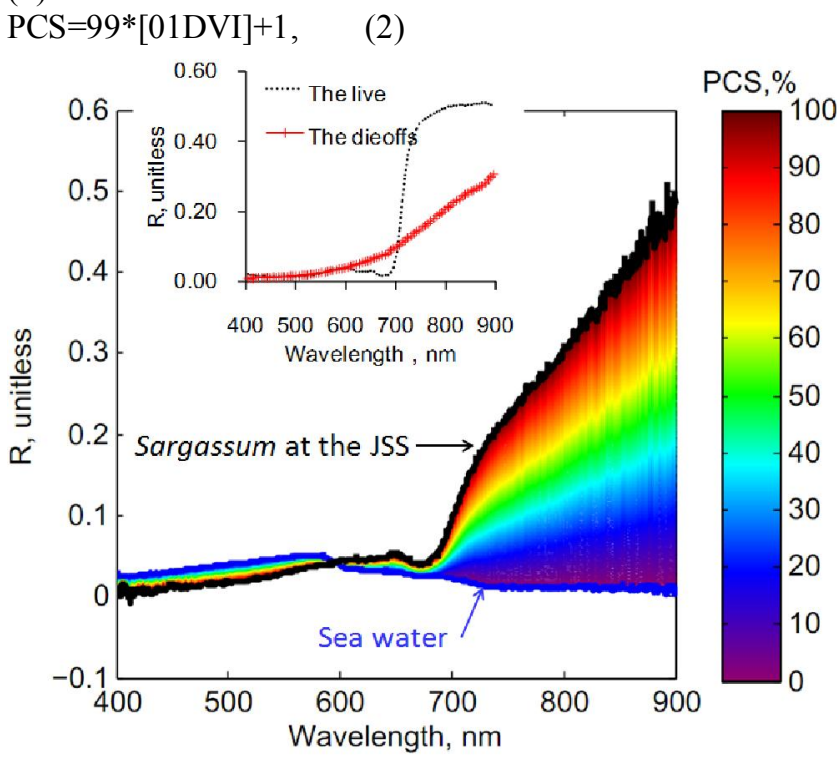

Fig. 1 The reflectance ( $R$, unitless), which is linearly mixed with the endmember reflectance of Sargassum horneri and that of sea water. The reflectance of Sagarrsum indicates its unhealthy status. The inset shows the reflectance of live Sargassum and the dieoffs (unpublished data).

For high-resolution images of MABs, it is reasonable to assume that there are pixels of macroalgae. For the macroalgae pixels extracted from the GF-1 WVF images, their DVI values are also normalized to be [01DVI]. Then, the above regression 
model (Eq. 2) is applied to estimate the PCS of each macroalgae pixel, and finally, the total abundance (real covering area) is estimated by summing up the macroalgae-covering area of each pixel.

\section{RESULTS AND DISCUSSION}

From the GF images acquired in September 2016, no macroalgae raft is found. From October 2016 on, macroalgae rafts are found every month. As shown in Fig. 2a, the spatial overlaps of MABs detected from each two successive images indicate a southward drifting path, i.e., from the coastal waters near the eastern end of the Shandong Peninsula to the Jiangsu Shoal. The MABs initially occurred on 18-Oct-2016 in the western Yellow Sea, about $50 \mathrm{~km}$ away from the south coast of the eastern Shandong Peninsula. One month later, the MABs drifted southwardly and extended mainly in the middle of the western Yellow Sea on 15-Nov-2016. On 2-Dec-2016, the MABs occurred over a large surface of the Jiangsu Shoal, and the zone affected by the MABs shifted southward to the north border of the turbid plumes of the Jiangsu Shoal. On 31-Dec-2016, most MABs aggregated in the Jiangsu Shoal, and caused severe damages to the local Poryphyra yezoensis aquaculture; meanwhile, a part of the MABs reached the Yangtze River Estuary in the East China Sea.

In the field validation work carried in the Jiangsu Shoal on the same day of 31-Dec-2016, the macroalgae was sampled and identified as brown macrolagae - Sargassum horneri (Figs. $2 \mathrm{~d}$ and e). Afterward, the Sargassum rafts continued to move southward, and most of them were located in the East China Sea by the end of January 2017. This work (Fig. 2) suggests that the Sargassum causing hazard in the Jiangsu Shoal came from the waters near the Shandong Peninsula, rather than originated in the Jiangsu Shoal. In our field work at the end of July 2016, large amount of Sargassum horneri was observed in the marine aquaculture area at the eastern end of the Shandong Peninsula (Fig.3a). Unfortunately, neither the total biomass nor the changes in the following months were recorded. However, these Sargassum might have been removed from the aquaculture facilities and released into the sea during the aquaculture activities, contributing to the golden tide in the Yellow Sea at the end of 2016.

Fig. 3a shows the spatial distributions of Sargassum detected from the GF-1 WVF images acquired on different dates, and Table 1 lists the corresponding total area of macroalgae pixels. Due to the presence of clouds over the study area on some days (Table 2), we cannot carry out an accurate assessment on the evolution of the golden tides. The results show an increase in the scale during the period from October to December of 2016, which implies some growth of Sargassum while drifting. However, the exact cause of the expansion of the golden tides needs to be investigated.

On 31-Dec-2016, the impacted area by Sargassum reached $20,000 \mathrm{~km}^{2}$, and 179713 pixels (with an area of $46.1 \mathrm{~km}^{2}$ in total) in images are contaminated by floating Sargassum. The magnitude of the golden tide is comparable to that of the MABs observed in the East China Sea on 27-Mar-2012 [12]. The PCS of each pixel containing Sargassum is estimated, and the total area of sea surface completely covered by Sargassum on 31 -Dec-2016 is estimated to be $8.8 \mathrm{~km}^{2}$ which can be further used to estimate the wet-weight biomass if we know the unit wet weight of Sargassum (e.g., $3 \mathrm{~kg} \mathrm{~m}^{-2}$ ). These data are useful for the economic assessment on collecting Sargassum as bio-resources as well as mitigating the negative impacts of the golden tide. It should be noted that the area coverage estimated in this study is lower than the actual one, because the pixels with low Sargassum count cannot be detected from the images with the resolution of $16 \mathrm{~m}$.

Table 2 The total area of macroalgae pixels detected from GF-1 WVF images over the Yellow Sea

\begin{tabular}{c|c|c|c|c|c}
\hline Date & $\begin{array}{c}18 \text {-Oct- } \\
2016^{*}\end{array}$ & $\begin{array}{c}15-N o v- \\
2016^{*}\end{array}$ & $\begin{array}{c}2-\text { Dec- } \\
2016\end{array}$ & $\begin{array}{c}31-\mathrm{Dec}- \\
2016\end{array}$ & $\begin{array}{c}24-J a n- \\
2017^{*}\end{array}$ \\
\hline $\begin{array}{c}\text { Area } \\
\mathrm{km}^{2}\end{array}$ & 2.2 & 22.2 & 50.1 & 46.1 & 15.2 \\
\hline
\end{tabular}

*There was large amount of clouds over the study area on the day.

As shown in Fig.1, we used only one pair of endmember reflectance of Sargassum and sea water, which might lead to uncertainties in estimating the PCS from large-scale satellite images, especially due to the variation in water constituents and physiological status of Sargassum. However, for the estimation of Sargassum in the Jiangsu Shoal in winter, the uncertainty should be reduced because the Sargassum rafts were mainly distributed in the relatively homogeneous turbid waters. The floating Sargassum at different phase of life cycle has different pigment contents, which are related to different physiological statuses, and thus has different reflectance (as shown in Fig. 1). The normalization of [01DVI] shown in this study can reduce the impacts from the changes in reflectance when multi-temporal images are acquired, which is useful for the estimation and comparison of biomass. It should be noted that the normalization of [01DVI] is also applicable to other indices, e.g., the Virtual-Baseline Floating macroAlgae Height (VB-FAH) and the Floating Algae Index (FAI), both of which are linear to the DVI [12].

Distinct distribution patterns can be seen in images with higher spatial resolutions. Figs. $3 \mathrm{~b}$ and c show the Sargassum slicks trapped by eddies in the 8-m false color image and the 2-m pan band, respectively. Figs. $3 d$ and e show the Sargassum patches in very turbid waters in the 4-m false color image and the 1-m pan band, respectively. The signals of small-scale Sargassum patches are usually too subtle to be detected in much coarser images, especially under optically-complex conditions. For example, on 31-Dec-2016, no macroalgae was detected by MODIS with the resolutions of 250, 500 and $1000 \mathrm{~m}$, while the simultaneous GF-1 WVF with $16-\mathrm{m}$ resolution clearly revealed the Sargassum rafts (Figs. $2 \mathrm{~b}$ and c) and provided detailed spatial information (Fig. 4).

Compared with other similar optical sensors like Landsat-8 and HJ-1 [12], the GF-1 WVF cameras have advantages in spatial resolution $(16 \mathrm{~m})$ and revisit cycle (4 days), which highly improve the capability in detecting early MABs and monitoring the temporal change in spatial distribution. The high spatial resolution also increases the chance of finding pixels of macroalgae in images, i.e., the macroalgae endmember; thus, it is possible to estimate the portion of macroalgae in each pixel as shown in this study and other endmember-associated approaches [14], [15]. 


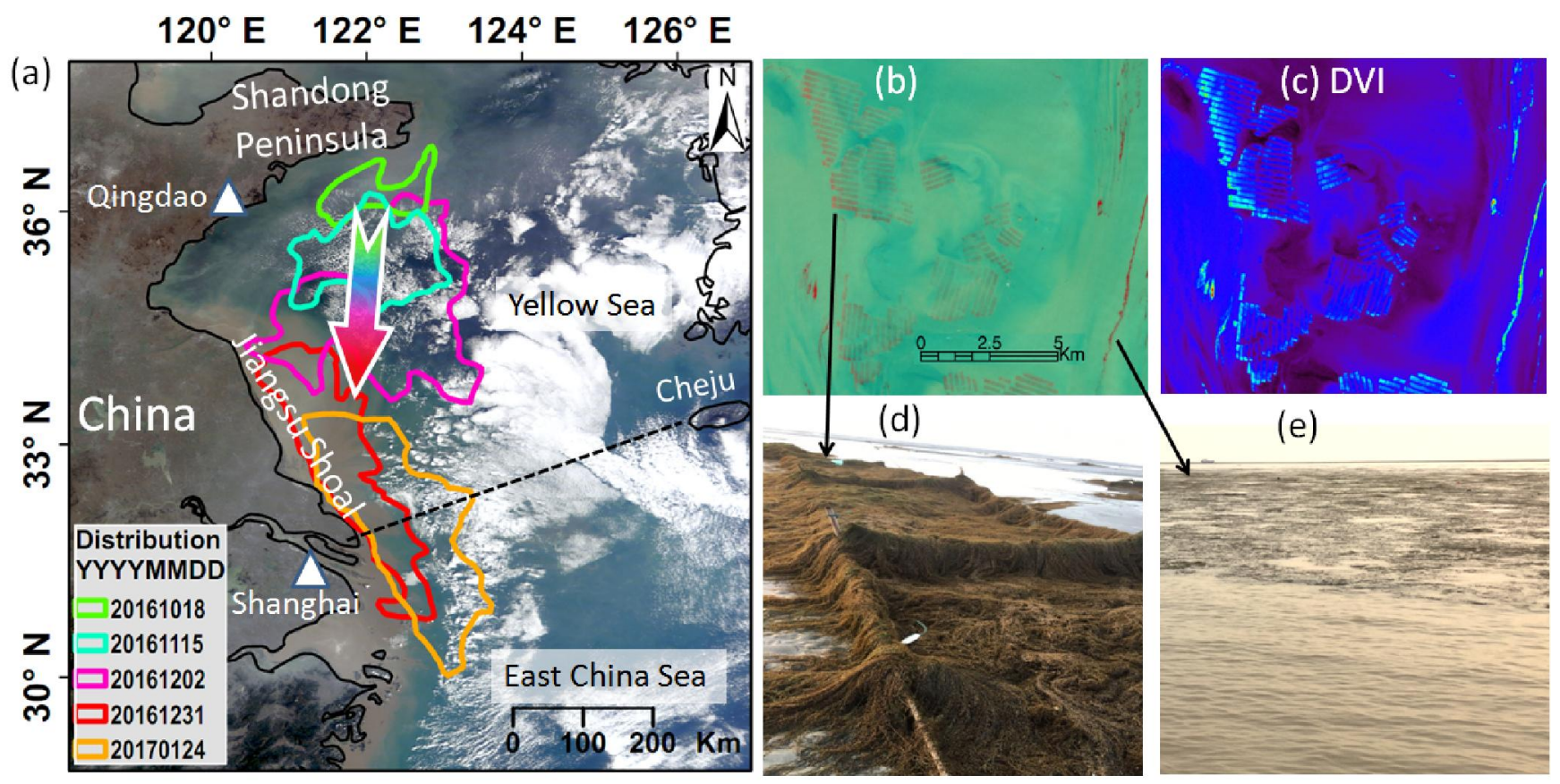

Fig. 2 (a) The southward drifting path of Sargassum patches during the period from October 2016 to January 2017 (the background image is a true color composite by MODIS bands acquired on 31-Dec-2016). (b) The false color image over the Jiangsu Shoal on the same day, which is a composite of GF-1 band 4(R), 3(G) and 2(B); the regularly-distributed red strips are the seaweed aquaculture rafts while the irregular red slicks or patches are floating Sargassum. (c) The image of DVI that ranges from -0.090 to 0.076. (d) and (e) In-situ photos of Sargassum covering the seaweed facilities and in the turbid waters, respectively.

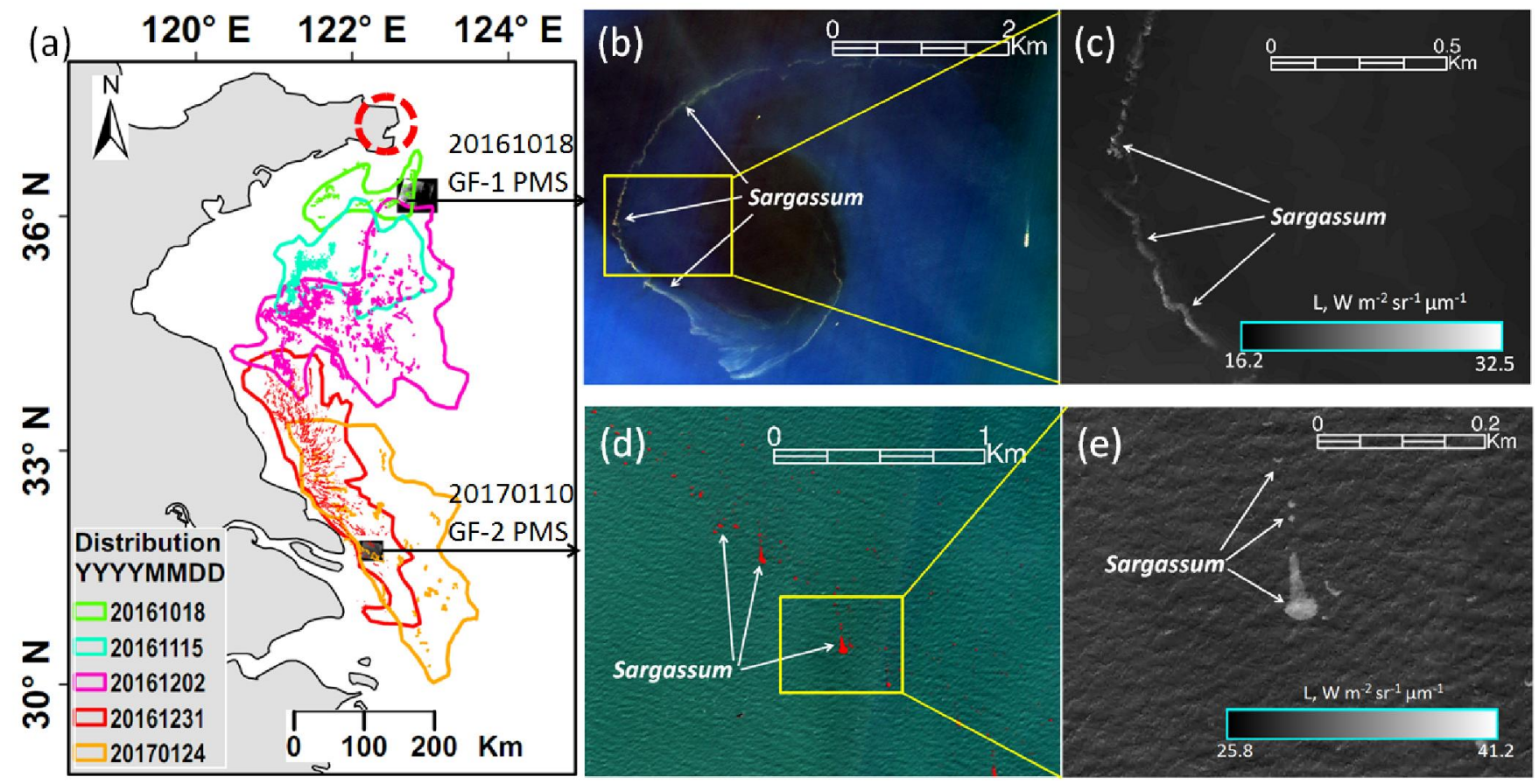

Fig. 3 (a): Map of the Sargassum-impacted areas and the high-resolution images over different sites. (b) and (c): Composite of band 4(R), 3(G), 2(B), and the pan band of GF-1 PMS, respectively. (d) and (e): Composite of band 4(R), 3(G), 2(B), and the pan band of GF-2 PMS, respectively. The bright and dark textures in (d) and (e) show clearly the sea surface swells and waves. The red-dashed circle shows the aquaculture area where floating Sargassum were observed at end of July, 2016. 


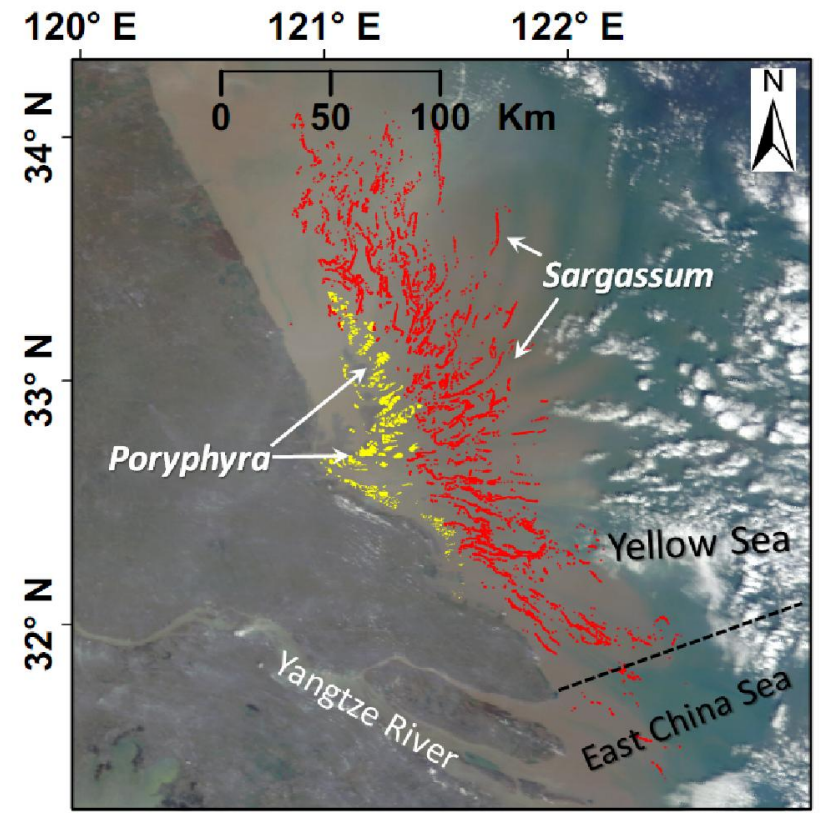

Fig. 4 The detected Sargassum rafts (red patches) from GF-1 WVF images in the Jiangsu Shoal on 31-Dec-2016. The seaweed aquaculture zones are marked in yellow. The background image is a true color composite by MODIS bands acquired on the same day, in which the very turbid waters in the Jiangsu Shoal are shown.

\section{CONCLUSIONS AND PERSPECTIVES}

In this work, with the aid of high-resolution images, a new marine hazard of golden tides caused by floating Sargassum horneri and its southward drifting path from the Yellow Sea to the East China Sea, China are identified for the first time. Although the precise origin of the Sargassum rafts could not been identified, we present the initial site and a new source of Sargassum, which might have drifted into the East China Sea and contributed to the large-scale Sargassum blooms observed in the East China Sea in winter and early spring in recent years [12], [16], [17]. Sargassum horneri is widely distributed along the China's coast, and its abundance has increased in recently years, including off the Shandong Peninsula. Future work may reveal how the Sargassum rafts occurred in the waters near the Shandong Peninsula and the forces behind it, e.g., the aquaculture activities.

To mitigate potential damages caused by the golden tides in the Yellow Sea and the East China Sea in future, we suggest to establish an early warning system by detecting Sargassum rafts over the Yellow Sea and the East China Sea using the high-resolution remote sensing approach shown in this study. This approach may also be applied to investigating the origin of Sargassum blooms in the Gulf of Mexico and the Caribbean Sea and for early warning [2]. Other high-resolution satellites, e.g., the Sentinel-2 that has four bands similar to those of the GF-1 and with the spatial resolution of $10 \mathrm{~m}$ [18] may also be included in a satellite network to increase the revisit frequency.

\section{ACKNOWLEDGMENTS}

The Gaofen-1 satellite images are from the China Centre for Resources Satellite Data and Application (CRESDA). The MODIS images are from NASA. We thank Prof. Qinqin Lu at the Jiangsu Institute of Oceanology and Marine Fisheries, China for providing the in-situ photos and data, and Mr. Bo Jiang for acquiring the satellite images.

\section{REFERENCES}

[1] D. Liu, J.K. Keesing, Q. Xing, P. Shi. "World's largest macroalgal bloom caused by expansion of seaweed aquaculture in China". Mar Pollut Bull, vol.58, pp.888-895. 2009.

[2] J. Gower, E. Young, S. King. "Satellite images suggest a new Sargassum source region in 2011". Remote Sensing Letters, vol. 4, no. 8, pp. 764-773. 2013.

[3] V. Smetacek, A. Zingone. "Green and golden seaweed tides on the rise". Nature, vol. 504, no. 7478, pp.84-88. 2013.

[4] L. Qi, C. Hu, Q. Xing, S. Shang. "Long-term trend of Ulva prolifera blooms in the western Yellow Sea". Harmful Algae. vol.58. pp. 35-44. Sep. 2016.

[5] Xinhua News Agency, Xuanwu District, Beijing, China, (2017)[Online]. Available:http://www.js.xinhuanet.com/-01/11/c_1120284277.html, Accessed on: Jan. 15, 2017.

[6] C. Hu, M.X. He. "Origin and offshore extent of floating algae in Olympic sailing area". Eos Trans, vol. 89, no. 33, pp. 302-303. Aug. 2008.

[7] X.H. Wang, L. Li, X. Bao, L. Zhao. "Economic cost of an algae bloom cleanup in China's 2008 Olympic sailing venue”. Eos Trans. vol. 90, no. 28, pp. 238-239. 2009.

[8] J. Gower, C. Hu, G. Borstad, S. King. "Ocean color satellites show extensive lines of floating Sargassum in the Gulf of Mexico". IEEE Geosci. Remote Sens. Lett, vol. 44, no. 12, pp. 3619-3625. 2006.

[9] Q. Xing, H. Loisel, F.G. Schmitt, P. Shi, D. Liu, J.K. Keesing. "Detection of the green tide at the Yellow Sea and tracking its wind-forced drifting by remote sensing", Cesifo Working Paper. vol. 157, no. 3-4, pp.543-567. 2009.

[10] T. Cui, J. Zhang, L. Sun, Y. Jia, W. Zhao, Z. Wang, J. Meng. "Satellite monitoring of massive green macroalgae bloom (GMB): imaging ability comparison of multi-source data and drifting velocity estimation". Int. J. Remote Sens., vol. 33, no. 13, pp. 5513-5527. 2012.

[11] Q. Xu, H. Zhang, Y. Cheng, S. Zhang, W. Zhang. "Monitoring and Tracking the Green Tide in the Yellow Sea With Satellite Imagery and Trajectory Model”. IEEE J. Sel. Topics Appl. Earth Observ.in Remote Ses., vol. 9, no. 11, pp. 5172-5181.2016.

[12] Q. Xing, C. Hu. "Mapping macroalgal blooms in the Yellow Sea and East China Sea using HJ-1 and Landsat data: Application of a virtual baseline reflectance height technique". Remote Sens. Environ. vol.178, pp. 113-126. 2016.

[13] Q. Xing.et al. "Monitoring "Green Tide" in the Yellow Sea and the East China Sea using multi-temporal and multi-source remote sensing images". Spectroscopy and Spectral Analysis, vol. 31, no. 6, pp. 1644-1647. 2011.

[14] C. Hu, L. Feng, R.F. Hardy, E.J. Hochberg. " "Spectral and spatial requirements of remote measurements of pelagic Sargassum macro algae”. Remote Sens. Environ., vol. 167, pp. 229-246. 2015

[15] Y. Xiao, J. Zhang, T. Cui. "High-precision extraction of nearshore green tides using satellite remote sensing data of the Yellow Sea, China”. Int. J. Remote Sens., vol. 38, no. 6, pp. 1626-1641. 2017

[16] T. Komatsu, et al. "Unusual distribution of floating seaweeds in the East China Sea in the early spring of 2012". J Appl Phycol . vol. 26, no. 2, pp. 1169-1179. 2014

[17] Q. Xing, X. Wang, L. Li. "Detection of winter macroalgal blooms (2014-2015) in the East China Sea using HJ-1 and Landsat data". Workshop program and book of abstracts of the 7th International Workshop on Modeling the Ocean, Canberra, Australia, pp. 42. 2015.

[18] ESA. [Online]. Available: https://sentinel.esa.int/, Accessed on: May 10, 2017. 